\title{
Breve histórico e classificação da vegetação capixaba
}

\author{
Brief history and classification of capixaba vegetation
}

\author{
Mário L. Garbin ${ }^{1,5}$, Felipe Z. Saiter ${ }^{2}$, Tatiana T. Carrijo ${ }^{3}$ \& Ariane L. Peixoto ${ }^{4}$
}

\begin{abstract}
Resumo
O estado do Espírito Santo apresenta grande variedade de ecossistemas num território relativamente pequeno. A exuberância de suas florestas vem despertando o interesse de muitos naturalistas e viajantes desde o século XIX, os quais deixaram registros valiosos dos primeiros anos da ocupação das "Areas Prohibidas" a leste de Minas Gerais. O cultivo do café, um dos alicerces econômicos do estado, deu início à perda dessas florestas. Tais perdas alavancaram o movimento conservacionista e a pesquisa científica no estado. A biogeografia, riqueza de espécies e de processos ecológicos nos fragmentos que restaram no Espírito Santo ainda revelam surpresas. Dentro do domínio da Floresta Atlântica, o estado abriga diferentes tipos de vegetação: Floresta Ombrófila Densa, Floresta Ombrófila Aberta, Floresta Estacional Semidecidual, Savanas, Formações Pioneiras e Refúgios Ecológicos. A descrição e classificação da vegetação do Espírito Santo ainda está inacabada tendo em vista as incertezas levantadas por alguns estudos. Também não existe um mapa da vegetação que contemple adequadamente a diversificada vegetação. A despeito de tais limitações, apresentamos descrições sucintas sobre os tipos de vegetação que vêm sendo reconhecidos na literatura moderna.
\end{abstract}

Palavras-chave: conservação, Espírito Santo, fitogeografia, Floresta Atlântica.

\begin{abstract}
The Espírito Santo state has a great variety of ecosystems in a relatively small territory. The exuberance of its forests has awakened the interest of many naturalists and travelers since the nineteenth century, who left valuable recordings of these early years of occupation of the "Areas Prohibidas" (Prohibited Areas), East of Minas Gerais. The coffee crops, one of the economic basis of the state, started the loss of these forests. Such losses also boosted the conservationist movement and the scientific research in the state. The biogeography, species richness, and the ecological processes in the remaining fragments of the Espírito Santo still reveal surprises. Within the Atlantic Forest domain, the state shelters different vegetational types: Ombrophilous Dense Forest, Ombrophilous Open Forest, Seasonal Semideciduous Forest, Savannas, Pioneer Formations, and Ecological Refuges. The description and classification of the vegetation is still unfinished due to the uncertainties raised by some studies. Moreover, there is a lack of a vegetation map that adequately contemplates the diversified vegetation. Despite these limitations, we present short descriptions of the vegetation types that have been recognized in the modern literature.
\end{abstract}

Key words: conservation, Espírito Santo, phytogeography, Atlantic Forest.

"E ao longo das margens, nos arbustos e árvores que pendiam por cima do rio, haviam se desenvolvido ramagens pendentes de trepadeiras, tapeçarias fantásticas como as que vimos no Amazonas e que eram de tamanha beleza que, para descrevê-las em sua encantadora abundância, a nossa língua é pobre demais." Princesa Therese von Bayern em 4 de agosto de 1888, ao passar pelo rio Doce, em Linhares (von Bayern 2013).

\footnotetext{
${ }^{1}$ Universidade Vila Velha, Lab. Ecologia Vegetal, Prog. Pós-graduação em Ecologia de Ecossistemas, R. Comissário José Dantas de Melo s/n, Boa Vista, 29102-770, Vila Velha, ES, Brasil.

${ }^{2}$ Instituto Federal de Educação, Ciência e Tecnologia do Espírito Santo, Rod. ES-080, Km 93, São João de Petrópolis, 29660-000, Santa Teresa, ES, Brasil.

${ }^{3}$ Universidade Federal do Espírito Santo/CCA, Lab. Botânica, Alto Universitário s/n, Guararema, 29500-000, Alegre, ES, Brasil.

${ }^{4}$ Instituto de Pesquisas Jardim Botânico do Rio de Janeiro, R. Pacheco Leão 915, Horto, 22460-030, Rio de Janeiro, RJ, Brasil.

${ }^{5}$ Autor para correspondência: mlgarbin@gmail.com
} 


\section{Um pouco de história}

As paisagens, florestas e plantas do Espírito Santo sempre despertaram o interesse e a curiosidade de gerações de naturalistas, viajantes e pesquisadores. Totalmente inserido na Mata Atlântica, o Espírito Santo talvez tenha uma história sem paralelo no Brasil no que tange à sua relação com a natureza. Por muitos anos, a Coroa Portuguesa proibiu o povoamento, a construção de estradas e a realização de excursões aos "sertões de leste" (Egler 1951; Oliveira 2008). Essas terras a leste de Minas Gerais, eram chamadas de "Areas Prohibidas" e tinham como intuito servir de barreira natural a aventureiros e possíveis invasores das ricas minas de ouro a oeste (Oliveira 2008). Consequentemente, o Espírito Santo teve o seu desenvolvimento restrito a uma estreita faixa de menos de três léguas (pouco menos de $15 \mathrm{~km}$ ) da costa (Egler 1951). Se, por um lado, tal proibição trouxe prejuízos ao desenvolvimento da capitania, por outro lado, o confinamento da ocupação à faixa litorânea permitiu a preservação de extensas porções de terra. Em 1535, quando de forma pioneira foi fundada a "Vila do Espírito Santo", atual cidade de Vila Velha, 87\% do território capixaba era coberto por florestas (Atlas dos Ecossistemas do Espírito Santo 2008). O pioneirismo da ocupação do litoral não foi acompanhado da ocupação do interior do estado.

Saint-Hilaire, em sua viagem ao estado em 1818, afirmou não encontrar qualquer cultura a mais de oito léguas da costa; e que dava conta de "não mais de 24 mil almas" ou no máximo pouco menos de 41 mil habitantes (Saint-Hilaire 1974). Entre 1865 e 1866, o geólogo canadense C.F. Hartt viajou entre o Rio de Janeiro e a Bahia descrevendo a geologia e a geografia da região (Hartt 1870). Segundo ele, "Em parte alguma do Brasil, nem mesmo no Pará, vi uma floresta mais exuberante do que a do rio Doce" (Egler 1951). Ainda em 1888, a grande barreira de florestas densas, com áreas pouco habitadas e praticamente inacessíveis, chamou a atenção da princesa Therese von Bayern, em sua viagem de duas semanas à província, de 25 agosto a 12 de setembro (von Bayern 2013). Ela estimou a população toda do estado em pouco mais de 121 mil habitantes. Somente a cidade do Rio de Janeiro já contava com mais de 500 mil habitantes por volta de 1890 (IBGE 2010). Durante quase 300 anos, esse era o resultado da política portuguesa de ocupação do território capixaba. $\mathrm{O}$ desenvolvimento acanhado e o confinamento ao litoral não passaram despercebidos pelos primeiros naturalistas a viajar pelo estado. A princesa Therese von Bayern infere, em suas anotações, que por volta de 1880 apenas $15 \%$ da área do estado havia sido ocupada por imigrantes europeus (von Bayern 2013). A efetiva colonização do estado ocorreu somente a partir da segunda metade do século XIX, com as primeiras levas de imigrantes europeus ocupando as regiões serranas e, a seguir, a região norte do rio Doce (Egler 1951). A ocupação promoveu a derrubada de florestas. Nesse período, a principal fonte econômica da agricultura do estado, o café, substituiu as florestas nativas (Dean 2004). Ao final da primeira metade do século XX, pouco da exuberância das visões dos primeiros viajantes e naturalistas havia restado (Egler 1951).

O historiador Levy Rocha (1971) oferece uma revisão sobre as viagens dos naturalistas que se aventuraram pelo estado e deixaram registros da flora, da fauna, da geografia, da geologia e da população. Dentre outros, citam-se os nomes seguidos do ano da visita: M. Rugendas (1824); A. Guisbright (1836); T. Peckolt (1850); G. Freyreiss, príncipe de Wied-Neuwied e F. Sellow (1815); C.F. Hartt (1865-1866), W. Steains (1885); A. Saint Hilaire (1818); e a princesa T. Bayern (1888), dentre outros nomes. Moritz Rugendas, aventurando-se pelas matas capixabas a partir de Minas Gerais em 1824, foi talvez o primeiro a registrar em desenhos a vegetação e a população local (Rocha 1971). Especula-se que Sellow tenha morrido em terras capixabas, por afogamento no rio Doce (Rocha 1971). É importante ressaltar que o Espírito Santo não estava na escala dos navios que iam para as Índias Orientais, como estavam a Bahia e o Rio de Janeiro (Rocha 1971). Para o leitor não familiarizado com a geografia do estado, é possível consultar o mapa interativo do portal I3Geo, do Instituto Estadual de Meio Ambiente e Recursos Hídricos (IEMA 2017), disponível em $<$ https://iema.es.gov.br/> para acessar informações geográficas e dados oficiais sobre localidades, municípios e áreas protegidas do Espírito Santo.

Quando entramos no século XX, Egler (1951) destaca o papel de Philipp von Luetzelburg (1880-1948), engenheiro e botânico alemão, que em sua passagem pelo Espírito Santo traz à tona um dos muitos mistérios das matas capixabas, o qual transcrevemos aqui: "Causa estranheza o contraste da vegetação na margem sul e norte do rio Doce. A vegetação da margem sul começa numa capoeira higrófila, passa depois a semi-xerófíla e transforma-se por completo em vegetação xerófila 
com aspecto de caatinga, a que o baiano, sem dúvida, daria a denominação de caatinga suja [...]. Atravessando, porém, o rio, na margem oposta nos recebem imediatamente as matas virgens. Eis o contraste palpitante". Egler (1951), ressalta que, por volta de 1950 , tal contraste já não era mais evidente devido à devastação das matas. A década de 1930 foi marcada por uma nova constituição, a de 1934, a implementação de um novo Código Florestal, e as bases para a organização de parques nacionais e estaduais (Dean 2004). Essas mudanças reverberaram no Espírito Santo concorrendo para tal o empenho de dois conservacionistas militantes: Álvaro Coutinho Aguirre (1899-1987) e Augusto Ruschi (1915-1986).

Álvaro Coutinho Aguirre, zoólogo do Ministério da Agricultura, exerceu, entre outros, o cargo de chefe da Divisão de Pesquisa desse ministério e propugnou, na década de 1940, para o estabelecimento no norte do Espírito Santo de duas áreas protegidas: a Reserva Florestal Estadual do Barra Seca, criada em 1941, e o Parque de Refúgio de Animais Silvestres Sooretama, criado em 1943. Não satisfeito, defendeu em diversos fóruns pela junção delas, o que ocorreu definitivamente em 1982 quando a Reserva Biológica de Sooretama foi estabelecida com os atuais limites. Esta área, juntamente com a Reserva Natural Vale, além de duas Reservas Particulares do Patrimônio Natural (Mutum Preto e Recanto das Antas) compõem o maior bloco contínuo de vegetação remanescente do estado, com cerca de 53 mil hectares, e último refúgio da onça pintada (Panthera onca) no Espírito Santo (ver Srbek-Araujo \& Kierulff 2016).

Augusto Ruschi esteve também vinculado a essas lutas e conquistas, e a muitas outras, tornando-se um dos grandes nomes do movimento ambientalista do país, patrono da ecologia brasileira que chegou a estampar cédulas de 500 cruzados novos em 1990. Não cabe aqui uma revisão do papel, história e legado desse capixaba, fundador do Museu de Biologia Prof. Mello Leitão. Para tal, o leitor pode buscar o livro "Ruschi O Agitador Ecológico", de Rogério Medeiros (1995), assim como o "Catálogo do Acervo Textual de Augusto Ruschi no Instituto Nacional da Mata Atlântica", de Alyne Gonçalves e Marcello Furtado (2015). $\mathrm{Na}$ introdução a esse catálogo Alyne Gonçalves destaca "três momentos na rica história de Ruschi, nos quais pesquisa, militância, convicções pessoais e posição institucional se confundiram e se retroalimentaram: a idealização e demarcação de sete reservas biológicas para a proteção integral da fauna e flora de determinadas regiões capixabas, entre 1940 e 1950; a disputa judicial travada com o governador do estado pela propriedade da estação biológica do Museu Nacional [parte da Estação Biológica Santa Lúcia], nos anos 1970; e a atuação no processo de sustação do desmatamento promovido pelo grupo Monteiro Aranha na Fazenda São Joaquim, nos anos 1980." Warren Dean (2004), tratando da história da devastação da Mata Atlântica, referiu-se a Ruschi como um "naturalista autodidata do Espírito Santo, de índole inteiramente avessa a concessões aduladoras por parte da elite governamental", e ressalta o papel de Ruschi na preservação das florestas de Santa Teresa, principalmente da Estação Biológica de Santa Lúcia, e das reservas biológicas de Sooretama e Comboios. Sobre a Estação Biológica de Santa Lúcia, podemos encontrar uma vasta literatura científica publicada. Destacamos, como exemplo, que ela possui riqueza de mamíferos (62 espécies), superada apenas pela "Manu Biosphere Reserve", no Peru (Passamani et al. 2000). Sua floresta apresenta um dos maiores índices de diversidade ecológica para o componente arbóreo já registrado entre as florestas tropicais $\left(H^{\prime}=5,2\right)$ (Saiter et al. 2011). Para outros grupos de organismos, como aves e lepidópteros, a riqueza de espécies também é alta (Mendes \& Padovan 2000). Se a floresta da Estação Biológica de Santa Lúcia tivesse sucumbido ao arrendamento de terras para dar lugar a plantações de palmeiras (Dean 2004), não poderíamos sequer ter imaginado esses achados. O Museu de Biologia Prof. Mello Leitão sedia o primeiro herbário capixaba criado em 1949 (Rede Brasileira de Herbários 2017) e se tornou a semente do atual Instituto Nacional da Mata Atlântica (INMA), criado em 6 de fevereiro de 2014 pela Lei 12.954, do qual projeta-se um papel de liderança e inovação em pesquisas de biodiversidade no estado e no país (Scarano 2016). Instituições como o INMA, que administram áreas preservadas, possuem grande relevância científica, social e biológica (Costa et al. 2016). Essa visão de avanço calcado pela responsabilidade ambiental e social esteve presente nas palavras de Ruschi, citadas em Medeiros (1995): "Não só a população do nosso país, mas toda a humanidade verá a exacerbação dos prejuízos causados pela presença e ação do homem, se o progresso não for encarado sob o ponto de vista ecológico". Assim, os esforços de Ruschi geraram frutos de valor inestimável para a ciência capixaba e o país, de longe superiores aos que as plantações teriam dado. 
Os remanescentes vegetais do estado, de modo geral, ainda carecem de muito aprofundamento no conhecimento de sua riqueza biológica. Muitos trechos vegetados, mesmo em unidades de conservação, apenas há poucos anos começaram a ter sua vegetação inventariada e documentada em coleções científicas. Outros, entretanto, destacamse por abrigarem inúmeras ações de pesquisas e de conservação nelas realizadas há algumas décadas e amplamente divulgadas. Entre estas, destaca-se a Reserva Natural Vale na floresta sobre tabuleiros costeiros (ver entre outros Rolim et al. 2016a com algumas sínteses de conhecimento; e Magnago et al. 2014), a Reserva Biológica de Santa Lucia, na floresta ombrófila densa (ver entre outros, Saiter el al. 2011), e as restingas, especialmente no Parque Estadual Paulo César Vinha (ver diversas publicações de Pereira e colaboradores, como Pereira \& Assis 2000). Entretanto, os resultados obtidos para áreas ainda pouco exploradas também já apontam para uma riqueza incomum. Uma área de Floresta Ombrófila Densa (ver descrição desse tipo de vegetação na próxima seção) com pouco mais de 150 ha ao sul do estado, no Parque Estadual de Mata das Flores (município de Castelo) revelou riqueza de 239 espécies de angiospermas e 21 novas ocorrências para o estado (Luber et al. 2016). No Parque Estadual de Itaúnas, em Conceição da Barra, município da região norte do estado, foram encontradas 562 espécies de angiospermas, o que representa mais de $74 \%$ de toda a riqueza de Angiospermas em restingas no Espírito Santo (Souza et al. 2016). A vertente capixaba (voltada para leste) do Parque Nacional do Caparaó, com áreas de Florestas Estacionais Semideciduais e Ombrófilas, ainda é pobremente conhecida. Sabese que essa região possui uma alta dissimilaridade com outras áreas montanas do país, provavelmente devido aos muitos endemismos (Zorzanelli et al. 2016a). Também na região do Caparaó capixaba, as lacunas de coleta são evidentes (Zorzanelli et al. 2017). A alta riqueza e o grande número de novas ocorrências indicam que as lacunas de coleta ainda são uma realidade e novas espécies são descobertas e descritas todos os anos no estado. Recentemente, foi descoberta uma nova espécie de Freziera (Pentaphylacaceae), a primeira do gênero conhecida para a Floresta Atlântica (Zorzanelli et al. 2016b) e mesmo bromélias de grande porte revelam-se como novas espécies (Coser et al. 2013). Tal carência de conhecimento ficou evidente numa listagem recentemente publicada que demonstrou que mesmo com o enorme esforço em estimar a riqueza de espécies do país, pelos especialistas colaboradores da Lista de Espécies da Flora do Brasil 2015 (BFG 2015), a riqueza de espécies conhecidas para o Espírito Santo estava subestimada em mais de 15\% (Dutra et al. 2015).

Além dessas incertezas inerentes ao estudo de ecossistemas de alta diversidade, muitos dos padrões de diversidade que temos hoje resultam da ação humana. No Espírito Santo, isto se deu não apenas pela perda ou degradação da vegetação nativa, mas também pela preservação e a regeneração de florestas na região serrana do estado. As primeiras levas de imigrantes que chegaram ao estado em 1847 (Egler 1951) precisavam derrubar a floresta para plantar as suas lavouras, e isso era feito com machado e fogo (Dean 2004; Seibel 2010). Para os imigrantes alemães da região serrana do Espírito Santo, era importante deixar parte da floresta intacta para sempre terem uma reserva de madeira disponível (Seibel 2010). Para lidar com um solo que rapidamente se esgotava após poucos ciclos de plantio, e que forçava a derrubada de novas áreas, eles adotaram uma técnica de descanso do terreno chamada de "capoeirão", mais conhecida como pousio, na qual o terreno era abandonado por três a quatro anos, uma "espécie de reflorestamento para a recuperação das terras" (Seibel 2010). Assim, a preservação e a regeneração de muitas áreas da região serrana do estado podem estar associadas às técnicas de recuperação do solo e a necessidade de madeira para as gerações futuras. Hoje sabemos que remanescentes de alta diversidade que compõem a paisagem rural estão associados a solos mais férteis (Athayde et al. 2016). Além disso, esses agricultores que preservam esses remanescentes criam condições favoráveis à conservação (GhelerCosta 2016). Assim como recentemente revelado para a floresta amazônica (Levis et al. 2017), é provável que muitos dos padrões de diversidade e composição observados hoje sejam resultado de ação humana, o que demandará novas linhas de pesquisa.

\section{A vegetação do Espírito Santo}

Iniciamos esta seção admitindo que a vegetação do Espírito Santo ainda não foi acuradamente descrita pelos trabalhos já publicados sobre o tema (p.ex., Ruschi 1950; Simonellli \& Fraga 2007). Também admitimos que são escassas na literatura as discussões acerca de inconsistências de classificação e delimitação dos tipos vegetacionais ali existentes (p.ex., Saiter et al. 2017; Rolim et al. 2016b). Sabemos, entretanto, 
que alguns botânicos e fitogeógrafos conhecedores das paisagens do Espírito Santo têm manifestado informalmente suas desconfianças a respeito da delimitação de tipos vegetacionais seguindo o Mapa de Vegetação do Brasil (IBGE 2004). As raízes desse mapa estão nos resultados dos relatórios sobre vegetação do Projeto RADAMBRASIL, que foi responsável pelo levantamento de recursos naturais em todo o território brasileiro por meio de imagens de radar (escala 1:250.000) e de satélite (Landsat 5 e 7; escala 1:500.000), além de ações de sobrevoo e amostragem em campo (Jordy Filho 1987). Os referidos relatórios adotaram o sistema de classificação de vegetação de Veloso \& GóesFilho (1982), um trabalho considerado precursor do atual sistema de classificação da vegetação brasileira de IBGE (2012), e tiveram detalhamento limitado ao nível de "formação".

No que se refere ao território do Espírito Santo, devemos considerar os mapas de vegetação apresentados pelo Projeto RADAMBRASIL para as folhas SF. 23/24 Rio de Janeiro/Vitória (Ururahy et al. 1983) e SE.24 Rio Doce (Jordy Filho 1987). A primeira folha abrangeu a porção sul do Espírito Santo, a partir da latitude de $20^{\circ} \mathrm{S}$, além de todo o território do Rio de Janeiro e de parte de Minas Gerais e São Paulo. A segunda abrangeu o restante do Espírito Santo, ao norte da latitude $20^{\circ} \mathrm{S}$, bem como parte dos territórios de Minas Gerais e Bahia. A análise desses mapas nos mostra que foram identificadas seis regiões fitoecológicas (aqui preferimos chamar de tipos de vegetação) no Espírito Santo: Floresta Ombrófila Densa, Floresta Ombrófila Aberta, Floresta Estacional Semidecidual, Savanas, Formações Pioneiras e Refúgios Ecológicos. Destas, apenas a tipologia de savanas não foi incorporada no mapa de IBGE (2004). Ressaltamos, contudo, que alguns tipos de vegetação somente reconhecidos em escala local, como a vegetação sobre afloramentos rochosos (inselbergs) e a vegetação de ilhas e ilhotas costeiras não mereceram destaque nos relatórios do Projeto RADAMBRASIL (Ururahy et al. 1983; Jordy Filho 1987) e no mapa de IBGE (2004).

Tendo como base apenas os seis tipos de vegetação descritos no Projeto RADAMBRASIL, propomos apresentar aqui descrições sintéticas de cada um, tendo como base as informações originais de Ururahy et al. (1983) e Jordy Filho (1987). Optamos pelas informações apresentadas nesses dois estudos, e não aquelas de aspecto geral do sistema de classificação da vegetação brasileira (IBGE 2012), pois elas tratam com maior especificidade a situação da vegetação do Espírito Santo. Adicionalmente, buscamos informar o leitor sobre dúvidas a respeito das áreas ocupadas pelos tipos vegetacionais, bem como relatar a provável existência de outros tipos.

A Floresta Ombrófila Densa é composta por árvores perenifólias com brotos foliares geralmente desprovidos de proteção à seca, e está subordinada a períodos secos de até 60 dias (Ururahy et al. 1983; Jordy Filho 1987). A princípio, a área delimitada para esse tipo de vegetação abrange os tabuleiros costeiros (Formação Barreiras) localizados entre as latitudes de $18^{\circ}$ a $21^{\circ} \mathrm{S}$, bem como terras mais elevadas e assumidamente mais úmidas do interior, tanto ao norte do rio Doce quanto na região serrana ao sul do mesmo rio (Fig. 1). Uma classificação hierárquica baseada sobretudo em critérios altitudinais também pode ser utilizada para indicar as formações de Floresta Ombrófila Densa: de Terras Baixas (até $50 \mathrm{~m}$ ), Submontana (50-500 $\mathrm{m})$, Montana (500-1500 m) e Alto-Montana (> $1500 \mathrm{~m}$ ).

Entretanto, existem fortes argumentos que dão suporte à classificação da floresta sobre tabuleiros costeiros da região de Sooretama e de Linhares (ao norte do rio Doce; Fig. 1 e Fig. $2 \mathrm{a}, \mathrm{b})$ como um tipo diferente de vegetação, com alternância temporal entre as fisionomias perenifólia e semicaducifólia ou semidecidual (denominado de floresta estacional perenifólia a semicaducifólia por Saiter et al. 2017). Além disso, estudos têm apontado que a parte centralnoroeste do Espírito Santo também seria área de predominância de florestas estacionais (Simonellli \& Fraga 2007; Saiter et al. 2015; Saiter et al. 2016). Como exemplo, citamos a floresta de São João de Petrópolis, no município de Santa Teresa, a qual é oficialmente classificada como Floresta Ombrófila Densa, mas que parece perder uma quantidade razoável de folhas durante o inverno (Fig. $1 \mathrm{e}$ Fig. 2c). Considerando essas situações à parte, as áreas protegidas e oficialmente reconhecidas no contexto da tipologia de Floresta Ombrófila Densa seriam: Estação Biológica de Santa Lúcia, Floresta Nacional de Goytacazes, Floresta Nacional do Rio Preto, Monumento Natural Serra das Torres, Parque Estadual de Forno Grande, Parque Estadual Mata das Flores, Parque Estadual de Pedra Azul, Parque Nacional do Caparaó, Parque Natural Municipal do Acaringa, Parque Natural Municipal da Fonte Grande, PNM de São Lourenço, Reserva Biológica Augusto Ruschi (Fig. 2d), Reserva Biológica Córrego do Veado, Reserva Biológica 


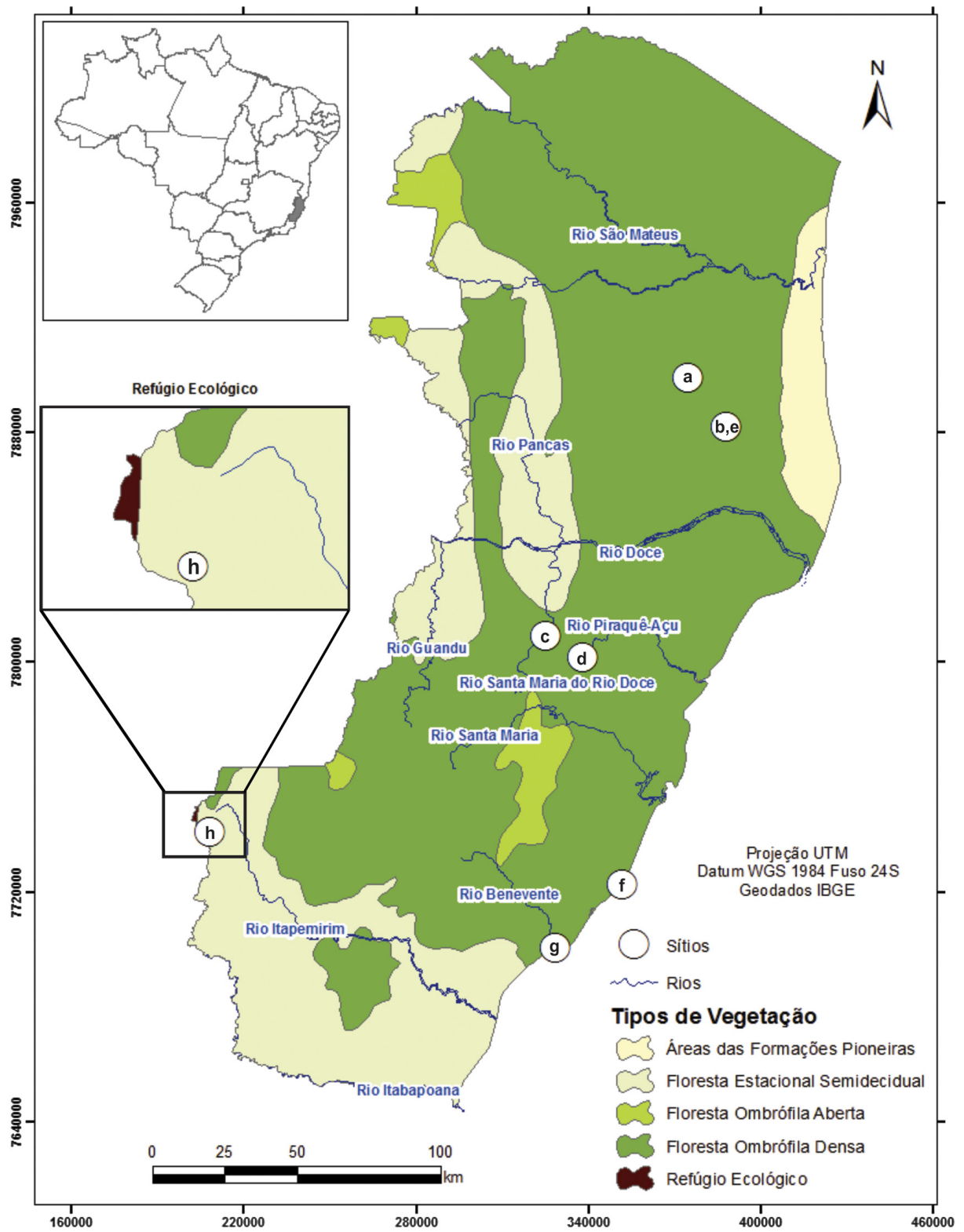

Figura 1 - Mapa mostrando os diferentes tipos de vegetação do estado do Espírito Santo (sensu IBGE 2004). Acima, à esquerda, mapa do Brasil com o estado do Espírito Santo em cinza. Letras correspondem a diferentes localidades cujas imagens são mostradas na Fig. 2. Os rios indicados no mapa correspondem aos citados no texto. Note que a delimitação da área de ocorrência de Refúgio Ecológico parece ter sido subestimada no mapa de IBGE (2004). Observar no texto indicações de possíveis inconsistências na classificação fisionômica dos sítios - a. vista aérea da floresta sobre tabuleiro, na Reserva Biológica de Sooretama; b. interior da floresta sobre tabuleiro na Reserva Natural Vale, em Linhares; c. floresta de São João de Petrópolis, em Santa Teresa; d. Reserva Biológica Augusto Ruschi, em Santa Teresa; e. campos nativos na Reserva Natural Vale, em Linhares; f. vegetação de restinga no Parque Estadual Paulo César Vinha, Guarapari; g. manguezal no estuário do rio Benevente, em Anchieta; h. Parque Nacional do Caparaó, na vertente voltada para o Espírito Santo, em Dores do Rio Preto. Figure 1 - Map showing the different vegetational types of the Espirito Santo state (sensu IBGE 2004). Top left, Brazil map with the Espirito Santo state in gray. Different letters correspond to different localities whose images are shown in Fig. 2. The rivers shown in the map are those cited in the text. Note that the area delimited for Ecological Refuge seems to be underestimated in the IBGE (2004) map. See text for indications of possible inconsistencies in the physiognomic classification of sites - a. aerial view of the forest on coastal tabuleiro, Sooretama Biological Reserve; b. interior of the forest on coastal tabuleiro in the Vale Natural Reserve, Linhares; c. São João de Petrópolis forest, Santa Teresa; d. Augusto Ruschi Biological Reserve, Santa Teresa; e. native fields in the Vale Natural Reserve, Linhares; f. restinga vegetation in the Paulo César Vinha State Park, Guarapari; g. magrove forest in the Benevente river estuary, Anchieta; h. Caparaó National Park, on the slope facing the Espírito Santo state, Dores do Rio Preto. 
Córrego Grande e Reserva Biológica de Duas Bocas, além de muitas Reservas Particulares do Patrimônio Natural (RPPN). Não obstante, algumas dessas áreas protegidas demandam estudos mais detalhados para uma classificação mais acurada de seus tipos vegetacionais.

A Floresta Ombrófila Aberta que ocorre no Espírito Santo é, segundo Ururahy et al. (1983), uma fisionomia florestal caracterizada por árvores mais espaçadas, sendo o caráter aberto estabelecido por palmeiras do gênero Attalea (Arecaceae). Esse tipo de vegetação foi mapeado (ver Fig. 1) em duas áreas disjuntas na região serrana ao sul do Rio Doce, a primeira entre Venda Nova do Imigrante e Ibatiba (1000-1200 m) e a segunda entre Alfredo Chaves e o sul de Santa Leopoldina (600-800 m) (Ururahy et al. 1983), e no extremo noroeste do estado, em parte dos atuais municípios de Mantenópolis e Água Doce do Norte (Jordy Filho 1987). Nesse último caso, sempre em altitude acima de $600 \mathrm{~m}$ e condicionado a um clima com até 90 dias secos (Jordy Filho 1987). Considerando as cotas altitudinais dessas áreas, a Floresta Ombrófila Aberta estaria apenas representada pela formação Montana. No entanto, ainda existe muita incerteza com relação à conceituação desse tipo de vegetação no contexto do Espírito Santo. Apesar de nenhum estudo ter sido realizado sobre o tema localmente, sabemos que palmeiras do gênero Attalea são relativamente comuns em toda a região serrana do Espírito Santo (certamente menos do que espécies de outros gêneros, como Euterpe edulis Mart.), e que a presença delas não necessariamente está ligada a uma fisionomia aberta da vegetação. Por outro lado, não temos como emitir opiniões sobre a vegetação do extremo noroeste do estado, pois o pouco que resta dela ainda se mantém como incógnita. No que tange à proteção, existem apenas pequenas RPPN (em conjunto somando menos de 200 ha) na área indicada como de Floresta Ombrófila Aberta entre Alfredo Chaves e o sul de Santa Leopoldina.

A Floresta Estacional Semidecidual ocorre sob clima com duas estações bem definidas, uma chuvosa e outra seca (Ururahy et al. 1983; Jordy Filho 1987). O período seco dura entre 90 e 120 dias e acarreta uma estacionalidade foliar das árvores dominantes, as quais têm adaptações à deficiência hídrica (Ururahy et al. 1983; Jordy Filho 1987). Em relação à deciduidade do conjunto florestal, a porcentagem de indivíduos arbóreos caducifólios (e não espécies) alcança 20-50\% durante o período desfavorável (Ururahy et al. 1983). Analisando os mapas de Ururahy et al. (1983) e Jordy Filho (1987), notamos que esse tipo de vegetação abrange os tabuleiros costeiros do Sul, as bacias dos rios Itabapoana e Itapemirim (incluindo parte da Serra do Caparaó), e trechos a centro-oeste mais ou menos coincidentes com as bacias dos rios Guandu, Santa Maria do rio Doce e Pancas (todas sub-bacias do rio Doce; Fig. 1). Contudo, como mencionamos acima, é provável que todo o noroeste do Espírito Santo seja de fato área de abrangência da Floresta Estacional Semidecidual. Em termos de formações, podemos encontrar no Espírito Santo as Florestas Estacionais Semideciduais de Terras Baixas (até 50 $\mathrm{m})$, Submontanas (51-500 m) e Montanas (501$1500 \mathrm{~m})$. As unidades de conservação existentes em área de Floresta Estacional Semidecidual (considerando a possibilidade de maior extensão da área de ocorrência desse tipo de vegetação) são: Área de Proteção Ambiental Pedra do Elefante, Parque Estadual Cachoeira da Fumaça, Parque Nacional do Caparaó, Monumento Natural o Frade e a Freira, Monumento Natural dos Pontões Capixabas, Floresta Nacional de Pacotuba e várias RPPN.

A tipologia Savana foi mapeada por Jordy Filho (1987) como um único enclave dentro da região de Floresta Ombrófila Densa, especificamente em uma área de solos arenosos, com apenas $30 \mathrm{~km}^{2}$, localizada em região de tabuleiros costeiros ao norte da cidade de Linhares. Entretanto, o autor relatou a ocorrência de várias outras áreas savanícolas de pequeno tamanho na região, inclusive no interior da Reserva Florestal da Companhia Vale do Rio Doce (atual Reserva Natural Vale; a ocorrência também é confirmada para a Reserva Biológica de Sooretama), as quais não puderam ser apropriadamente delimitadas em virtude da escala de mapeamento. É possível que a única área de savana mapeada por Jordy Filho (1987) tenha sido suprimida do Mapa de Vegetação do Brasil (IBGE 2004) devido à mesma limitação de escala (Fig. 1). As Savanas descritas para o norte do Espírito Santo correspondem, sem dúvida, ao que se costuma denominar localmente de campos nativos (Fig. 1; Fig. 2e), um ambiente caracterizado por fitofisionomias herbáceas a herbáceo-arbustivas (ver Araujo et al. 2008). Devemos, por último, ressaltar a associação dessas savanas com a chamada floresta de muçununga, uma feição florestal adjacente também ocupando solos arenosos desestruturados, mas que é caracterizada por árvores de pequeno porte, em flagrante distinção fisionômica para com a floresta de maior porte que domina o entorno (Saporetti 

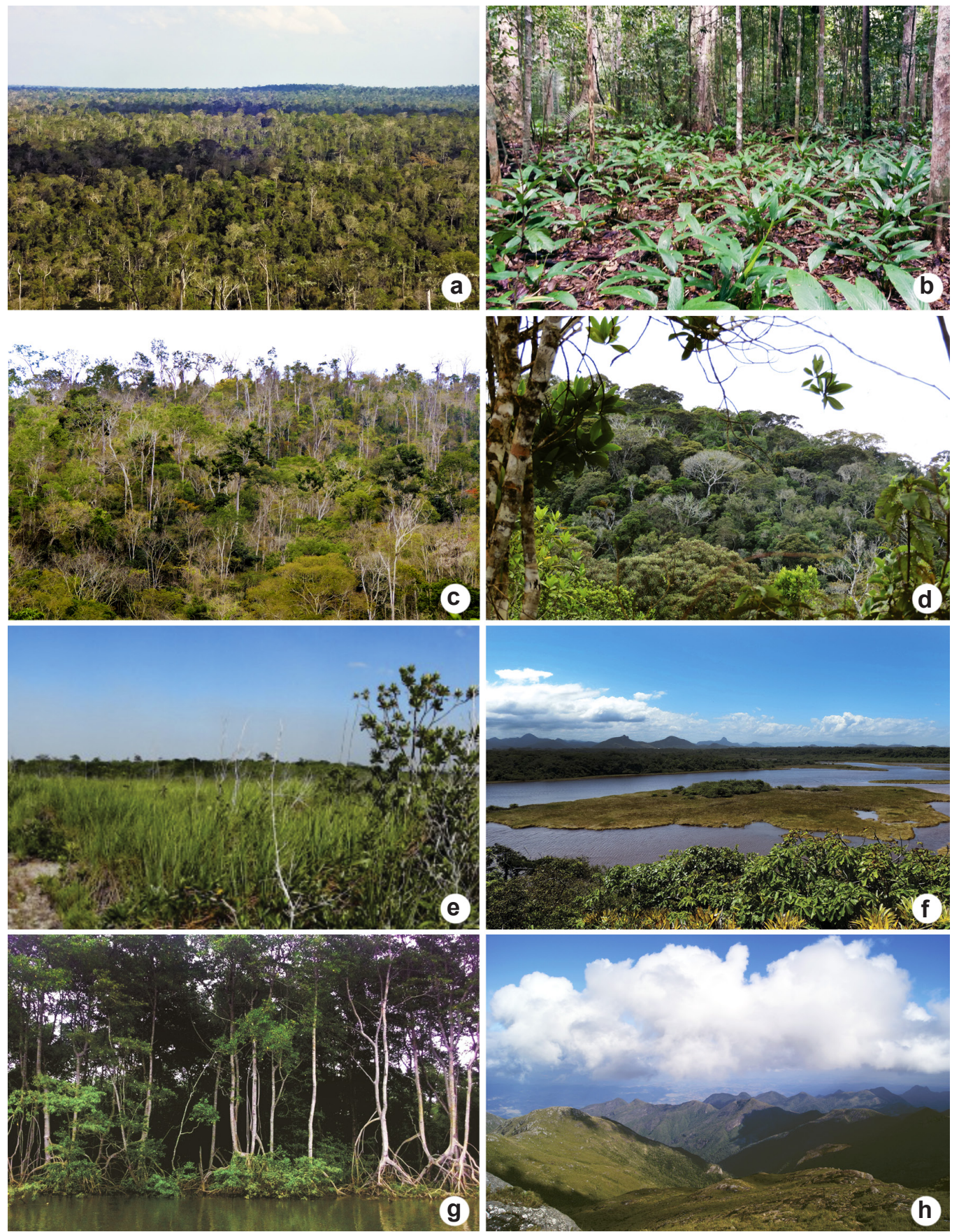

Figura 2 - Diferentes tipos de vegetação encontrados no estado do Espírito Santo - a. vista aérea da floresta sobre tabuleiro, na Reserva Biológica de Sooretama; b. interior da floresta sobre tabuleiro na Reserva Natural Vale, em Linhares; c. floresta de São João de Petrópolis, em Santa Teresa; d. Reserva Biológica Augusto Ruschi, em Santa Teresa; e. campos nativos na Reserva Natural Vale, em Linhares; f. vegetação de restinga no Parque Estadual Paulo César Vinha, Guarapari; g. manguezal no estuário do rio Benevente, em Anchieta; h. Parque Nacional do Caparaó, na vertente voltada para o Espírito Santo, em Dores do Rio Preto. Fotos: a,e. G.S. Siqueira; b,g,h. M.L. Garbin; c,d,f. F.Z. Saiter.

Figure 2 - Different vegetational types found in the Espírito Santo state-a. aerial view of the forest on coastal tabuleiro, Sooretama Biological Reserve; b. interior of the forest on coastal tabuleiro in the Vale Natural Reserve, Linhares; c. São João de Petrópolis forest, Santa Teresa; d. Augusto Ruschi Biological Reserve, Santa Teresa; e. native fields in the Vale Natural Reserve, Linhares; f. restinga vegetation in the Paulo César Vinha State Park, Guarapari; g. magrove forest in the Benevente river estuary, Anchieta; h. Caparaó National Park, on the slope facing the Espírito Santo state, Dores do Rio Preto. Photos: a,e. G.S. Siqueira; b,g,h. M.L. Garbin; c,d,f. F.Z. Saiter. 
Júnior et al. 2012; Simonelli et al. 2008), a típica floresta sobre tabuleiros costeiros mencionada anteriormente.

As Formações Pioneiras ocupam os depósitos de sedimentos do Quaternário (Fig. 1, mas atente para o fato de que a escala não permite visualizar todos esses depósitos no mapa) e podem ser divididas em áreas de influência marinha, influência fluvio-marinha e influência fluvial (Ururahy et al. 1983; Jordy Filho 1987). As áreas de influência marinha correspondem aos cordões arenosos e dunas que ocorrem ao longo do litoral (Ururahy et al. 1983). São caracterizadas por solos arenosos resultantes da deposição de areias marinhas e cobertas pela chamada vegetação de restinga, ou simplesmente restinga. Sob essa denominação está um rico conjunto de físionomias, as quais se diferenciam por aspectos ambientais, fisionômicos e florísticos (Fig. 2f). Devemos acrescentar que Pereira et al. (2003) adotou uma classificação prática das fisionomias de restinga composta pelas seguintes categorias: herbácea não inundável, herbácea inundável, herbácea inundada, arbustiva fechada não inundável, arbustiva fechada inundável, arbustiva aberta não inundável, arbustiva aberta inundada, florestal não inundável, florestal inundável, e florestal inundada. Nessa classificação, os termos inundável e inundada indicam, respectivamente, regime sazonal de inundação e regime permanente de inundação. Áreas de restingas protegidas mais relevantes são encontradas no Parque Estadual de Itaúnas, na Reserva Biológica de Comboios, no Parque Estadual Paulo César Vinha, na Área de Proteção Ambiental de Setiba, no Parque Natural Municipal de Jacarenema e na Área de Proteção Ambiental Guanandy.

As áreas de influência fluvio-marinha correspondem aos ambientes halófilos da desembocadura de curso de água no mar. Representam essas áreas os manguezais (com suas distintas comunidades) localizados na foz de alguns rios (por exemplo, os rios Piraquê-açu, Santa Maria e Benevente) (Fig. 2g), e a extensa planície inundada/inundável coberta por vegetação essencialmente herbácea nas proximidades da foz do rio Doce. As áreas de influência fluvial compreendem as planícies aluviais periodicamente ou permanentemente inundadas ocupando faixas extensas ao longo dos rios. Devido ao encharcamento dos solos, que limita a instalação de componente arbóreo, essas áreas são cobertas por uma vegetação herbáceo-graminóide. Esses tipos de vegetação estão legalmente protegidos em unidades de conservação como o Parque Estadual de Itaúnas, o Parque Natural Municipal de Jacarenema, a Reserva de Desenvolvimento Sustentável Concha D’Ostra, a Área de Proteção Ambiental de Conceição da Barra e aquelas que compõem o Mosaico de Áreas Protegidas da Baía de Vitória.

Os Refúgios Ecológicos são representados no Espírito Santo por uma formação Alto-Montana (também denominada de campos de altitude; Fig. 1) que é composta por vegetação de porte herbáceograminóide intercalada por pequenos arbustos e que ocorre sobre solos litólicos de embasamento cristalino acima de $1500 \mathrm{~m}$ de altitude na Serra do Caparaó (Fig. 1 e Fig. 2h). Simonelli \& Fraga (2007), entretanto, especularam sobre a possível ocorrência desse tipo de vegetação em outras áreas elevadas da região serrana do estado. É certo que existem outras localidades relativamente próximas à Serra do Caparaó e com altitudes compatíveis com esse tipo de vegetação, como o pico do Forno Grande (2039 m), a Pedra Azul (1822 m) e a Pedra das Flores (1909 m). Contudo, tais localidades são caracterizadas por maciços rochosos onde a formação de solos litólicos ocorre somente em pequenas e rasas depressões da superfície rochosa. Consequentemente, nesses locais os solos não adquirem extensão e complexidade como nos campos de altitude. Isso nos faz considerar que os campos de altitude estariam mesmo restritos ao Parque Nacional do Caparaó.

\section{Considerações finais}

Esperamos ter deixado evidente que as lacunas de conhecimento sobre a vegetação do Espírito Santo ainda são enormes. Talvez, um dos maiores desafios para a botânica capixaba ainda seja saber o tamanho da biodiversidade remanescente que ela guarda. Isto é a base para o futuro de outras áreas do conhecimento, como ecologia, genética, farmacologia e biologia da conservação. A princesa Therese von Bayern afirmou que a vegetação capixaba era "[...] de tamanha beleza que, para descrevê-la em sua encantadora abundância, a nossa língua é pobre demais". Apesar de a princesa ter referido à língua alemã, estendemos a reflexão à língua portuguesa e esperamos, fundamentalmente, que tal incapacidade não se reflita em uma ciência pobre demais para entender e preservar o pouco que restou. Este volume inicial da Flora do Espírito Santo dará bases para que uma nova geração de cientistas cumpra essa difícil tarefa. 


\section{Agradecimentos}

Agradecemos à FAPES, o financiamento de projetos que vêm propiciando aos autores avançar o conhecimento sobre a vegetação do Espírito Santo; ao $\mathrm{CNPq}$, a concessão da bolsa de Produtividade a T.T. Carrijo; a Geovane S. Siqueira e Acervo RNV, as fotografias da Reserva Natural Vale.

\section{Referências}

Araujo DSD, Pereira OJ \& Peixoto AL (2008) Campos nativos at the Linhares Forest Reserve, Espírito Santo, Brazil. In: Thomas WW (eds.) The Atlantic Coastal Forest of Northeastern Brazil. Memoirs of The New York Botanical Garden. The New York Botanical Garden Press, Bronx. Pp. 371-394.

Athayde EA, Cancian LF, Patricia L \& Morellato C (2016) The value of agricultural landscape for tropical trees. In: Gheler-Costa C, Lyra-Jorge MC, Martins-Verdade L (eds.) Biodiversity in agricultural landscapes of Southeastern Brazil. De Gruyter Open, Berlin. Pp. 87-111.

Atlas dos Ecossistemas do Espírito Santo (2008) Atlas dos ecossistemas do Espírito Santo. Governo do estado do Espírito Santo, Secretaria Estadual de Meio Ambiente e Recursos Hídricos, Vitória. 504p.

BFG - The Brazil Flora Group (2015) Growing knowledge: an overview of seed plant diversity in Brazil. Rodriguésia 66: 1085-1113.

Coser TS, Versieux LM \& Wendt T (2013) Alcantarea galactea (Bromeliaceae), a new giant bromeliad from Brazil, with populations seen from the sky. Systematic Botany 38: 339-343.

Costa MLMN, Wyse JP, Fernandes RA \& Peixoto AL (2016) Conservation of threatened plant species in botanic garden reserves in Brazil. Oryx: 1-8.

Dean W (2004) A ferro e fogo: a história e a devastação da Floresta Atlântica brasileira. Cia. das Letras, São Paulo. 484p.

Dutra VF, Alves-Araújo A \& Carrijo TT (2015) Angiosperm checklist of Espírito Santo: using electronic tools to improve the knowledge of an Atlantic Forest biodiversity hotspot. Rodriguésia 66: 1145-1152.

Egler WA (1951) A zona pioneira ao norte do Rio Doce. Revista Brasileira de Geografia Física 2: 55-264.

Gheler-Costa C (2016) The role of family farms in environmental conservation in agricultural landscapes. In: Gheler-Costa C, Lyra-Jorge MC, Martins-Verdade L (eds.) Biodiversity in agricultural landscapes of Southeastern Brazil. De Gruyter Open, Berlin. Pp. 14-27.

Gonçalves AS \& Furtado MF (2015) Catálogo do acervo textual de Augusto Ruschi no Instituto Nacional da Mata Atlântica (Museu de Biologia Prof. Mello Leitão). Above Publicações, Vila Velha. 452p.

Hartt CF (1870) Scientific results of a journey in Brazil. By Louis Agassiz and his travelling companions. Geology and physical geography of Brazil, by
Ch. Fred. Hartt, professor of Geology in Cornell University. Fields, Osgood, Boston. 620p.

IBGE - Instituto Brasileiro de Geografia e Estatística (2004) Mapa de vegetação do Brasil. $3^{a}$ ed. Instituto Brasileiro de Geografia e Estatística, Rio de Janeiro. Disponível em <ftp://ftp.ibge.gov.br/ Cartas_e_Mapas/Mapas_Murais/>. Acesso em 10 agosto 2017.

IBGE - Instituto Brasileiro de Geografia e Estatística (2010) Sinopse do censo demográfico 2010. População nos censos demográficos, segundo os municípios das capitais - 1872/2010. Disponível em $<$ http://www.censo2010.ibge.gov.br/sinopse/index. php?dados $=6 \& u f=00>$. Acesso em 8 julho 2017 .

IBGE - Instituto Brasileiro de Geografia e Estatística (2012) Manual técnico da vegetação brasileira. Série manuais técnicos em Geociências 1. 2a ed. Instituto Brasileiro de Geografia e Estatística, Rio de Janeiro. 275p.

IEMA - Instituto Estadual de Meio Ambiente e Recursos Hídricos (2017) i3Geo. Disponível em $<$ http://189.84.218.229/>. Acesso em 16 outubro 2017.

Jordy Filho A (1987) Vegetação: as regiões fitoecológicas, sua natureza e seus recursos econômicos. Estudo fitogeográfico. In: IBGE. Folha SE. 24 Rio Doce: geologia, geomorfologia, pedologia, vegetação e uso potencial da terra. Fundação Instituto Brasileiro de Geografia e Estatística, Rio de Janeiro. Pp. 553-624.

Levis C, Costa FRC, Bongers F, Peña-Claros M, Clement CR, Junqueira AB, Neves EG, Tamanaha EK, Figueiredo FOG, Salomão RP, Castilho CV, Magnusson WE, Phillips OL, Guevara JE, Sabatier D, Molino J-F, López DC, Mendoza AM, Pitman NCA, Duque A, Vargas PN, Zartman CE, Vasquez R, Andrade A, Camargo JL, Feldpausch TR, Laurance SGW, Laurance WF, Killeen TJ, Nascimento HEM, Montero JC, Mostacedo B, Amaral IL, Guimarães Vieira IC, Brienen R, Castellanos H, Terborgh J, Carim MJV, Guimarães JRS, Coelho LS, Matos FDA, Wittmann F, Mogollón HF, Damasco G, Dávila N, García-Villacorta R, Coronado ENH, Emilio T, Filho DAL, Schietti J, Souza P, Targhetta N, Comiskey JA, Marimon BS, Marimon B-H, Neill D, Alonso A, Arroyo L, Carvalho FA, Souza FC, Dallmeier F, Pansonato MP, Duivenvoorden JF, Fine PVA, Stevenson PR, Araujo-Murakami A, Aymard CGA, Baraloto C, Amaral DD, Engel J, Henkel TW, Maas P, Petronelli P, Revilla JDC, Stropp J, Daly D, Gribel R, Paredes MR, Silveira M, Thomas-Caesar R, Baker TR, Silva NF, Ferreira LV, Peres CA, Silman MR, Cerón C, Valverde FC, Di Fiore A, Jimenez EM, Mora MCP, Toledo M, Barbosa EM, Bonates LCM, Arboleda NC, Farias ES, Fuentes A, Guillaumet J-L, Jørgensen PM, Malhi Y, Andrade Miranda IP, Phillips JF, Prieto A, Rudas A, Ruschel AR, Silva N, von Hildebrand P, Vos VA, Zent EL, Zent S, Cintra BBL, Nascimento MT, Oliveira AA, Ramirez-Angulo H, Ramos JF, Rivas G, Schöngart 
J, Sierra R, Tirado M, van der Heijden G, Torre EV, Wang O, Young KR, Baider C, Cano A, Farfan-Rios W, Ferreira C, Hoffman B, Mendoza C, Mesones I, Torres-Lezama A, Medina MNU, van Andel TR, Villarroel D, Zagt R, Alexiades MN, Balslev H, Garcia-Cabrera K, Gonzales T, Hernandez L, Huamantupa-Chuquimaco I, Manzatto AG, Milliken W, Cuenca WP, Pansini S, Pauletto D, Arevalo FR, Reis NFC, Sampaio AF, Giraldo LEU, Sandoval EHV, Gamarra LV, Vela CIA, ter Steege H (2017) Persistent effects of pre-Columbian plant domestication on Amazonian forest composition. Science 355: 925-931. DOI: 10.1126/science. aal0157.

Luber J, Tuler AC, Torres F, Christ JA, Guidoni-Martins $\mathrm{KG}$, Zanetti M, Hollunder RK, Manhães VC, Zorzanelli JPF, Mendonça ES, Garbin ML \& Carrijo TT (2016) List of angiosperm species in an Atlantic Forest fragment reveals collection gaps in Espírito Santo state, Brazil. Check List 12: 1-10.

Magnago LFS, Edwards DP, Edwards FA, Magrach A, Martins SV \& Laurance WF (2014) Functional attributes change but functional richness is unchanged after fragmentation of Brazilian Atlantic forests. Journal of Ecology 102: 475-485.

Medeiros R (1995) Ruschi o agitador ecológico. Record, Rio de Janeiro. 223p.

Mendes SL \& Padovan MDP (2000)A Estação Biológica de Santa Lúcia, Santa Teresa, Espírito Santo. Boletim do Museu de Biologia Mello Leitão 11/12: 7-34.

Oliveira JT (2008) História do estado do Espírito Santo, $3^{\mathrm{a}}$ ed. Arquivo Público do Estado do Espírito Santo, Vitória. 670p.

Passamani M, Mendes SL \& Chiarello AG (2000) Nonvolant mammals of the Estação Biológica de Santa Lúcia and adjacent areas of Santa Teresa, Espírito Santo, Brazil. Boletim do Museu de Biologia Mello Leitão 11: 201-214.

Pereira OJ \& Assis AM (2000) Florística da restinga de Camburi, Vitória, Espírito Santo. Acta Botanica Brasilica 14: 99-111.

Pereira OJ (2003) Restinga: origem, estrutura e diversidade. In: Jardim MAG, Bastos MNC \& Santos JUM (eds.) Desafios da botânica brasileira no novo milênio: inventário, sistematização e conservação da biodiversidade vegetal. Sociedade Botânica do Brasil, Universidade Federal Rural da Amazônia.Museu Paraense Emílio Goeldi, Belém. Pp. 177-179.

Rede Brasileira de Herbários (2017) Sociedade Botânica do Brasil. Disponível em $<$ http://www.botanica. org.br/buscar_herbario pub.php $>$. Acesso em 20 junho 2017.

Rocha L (1971) Viajantes estrangeiros no Espírito Santo. EBRASA, Brasília. 190p.

Rolim SG, Menezes LFT de \& Srbek-Araujo AC (2016a) Floresta Atlântica de Tabuleiro: diversidade e endemismos na Reserva Natural Vale. Ed. Rupestre, Belo Horizonte. 496p.
Rolim SG, Ivanauskas NM \& Engel VL (2016b) As florestas de tabuleiro do norte do Espírito Santo são ombrófilas ou estacionais? In: Rolim SG, Menezes LFT \& Srbek-Araujo AC (eds.) Floresta Atlântica de Tabuleiro: diversidade e endemismos na Reserva Natural Vale. Ed. Rupestre, Belo Horizonte. Pp. 47-60.

Ruschi A (1950) Fitogeografia do Estado de Esp. Santo: considerações gerais sobre a distribuição da flora no estado do E. Santo. Boletim do Museu de Biologia Prof. Mello Leitão (Série Botânica) 1: 1-353

Saint-Hilaire A de (1974) Viagem ao Espírito Santo e Rio Doce. Ed. Itatiaia, Editora da Universidade de São Paulo, Belo Horizonte. 121p.

Saiter FZ, Guilherme FAG, Thomaz LD \& Wendt T (2011) Tree changes in a mature rainforest with high diversity and endemism on the Brazilian coast. Biodiversity and Conservation 20: 1921-1949.

Saiter FZ, Eisenlohr PV, França GS, Stehmann JR, Thomas WW \& Oliveira-Filho AT (2015) Floristic units and their predictors unveiled in part of the Atlantic Forest hotspot: implications for conservation planning. Anais da Academia Brasileira de Ciências 87: 2031-2046.

Saiter FZ, Brown JL, Thomas WW, Oliveira-Filho AT \& Carnaval AC (2016) Environmental correlates of floristic regions and plant turnover in the Atlantic Forest hotspot. Journal of Biogeography 43: 2322-2331.

Saiter FZ, Rolim SG, Jordy Filho S \& Oliveira-Filho AT (2017) Uma revisão sobre a controversa classificação fisionômica da Floresta de Linhares, norte do Espírito Santo. Rodriguésia 68: 18951907.

Saporetti Júnior AW, Schaefer CEGR, Souza AL, Soares MP, Araujo DSD \& Meira Neto JA (2012) Influence of Soil Physical Properties on Plants of the Mussununga Ecosystem, Brazil. Folia Geobotanica 47: 29-39.

Scarano FR (2016) Por que o Brasil precisa do Instituto Nacional da Mata Atlântica? Boletim do Museu de Biologia Mello Leitão 38: 7-10.

Seibel I (2010) Imigrante no século do isolamento/1870 -1970. Traço, São Leopoldo. 558p.

Simonellli M \& Fraga CN (2007) Espécies da flora ameaçadas de extinção no estado do Espírito Santo. Ipema, Vitória. 144p.

Simonelli M, Souza AL, Peixoto AL \& Silva AF (2008) Floristic composition and structure of the tree component of a Muçununga Forest in the Linhares Forest Reserve, Espírito Santo, Brazil. The New York Botanical Garden Press, New York. Pp. 345-364.

Souza WO, Machado JO, Tognella MMP \& AlvesAraújo A (2016) Checklist de angiospermas do Parque Estadual de Itaúnas, Espírito Santo, Brasil. Rodriguésia 67: 571-581.

Srbek-Araujo AC \& Kierulff MCM (2016) Mamíferos de médio e grande porte das florestas de Tabuleiro do norte do Espírito Santo: grupos funcionais e 
principais ameaças. In: Rolim SG, Menezes LFT \& Srbek-Araujo AC (eds.) Floresta Atlântica de Tabuleiro: diversidade e endemismos na Reserva Natural da Vale. Ed. Rupestre, Belo Horizonte. Pp. 469-479.

Ururahy JCC, Collares JER, Santo MM \& Barreto RAA (1983) Vegetação: as regiões fitoecológicas, sua natureza e seus recursos econômicos. Estudo fitogeográfico. In: IBGE. Folha SE. 23/24 Rio de Janeiro/Vitória: geologia, geomorfologia, pedologia, vegetação e uso potencial da terra. Fundação Instituto Brasileiro de Geografia e Estatística, Rio de Janeiro. Pp. 353-385.

Veloso HP \& Góes-Filho L (1982) Fitogeografia brasileira: classificação fisionômico-ecológica da vegetação neotropical. Boletim Técnico Projeto RADAMBRASIL, Série Vegetação, n ${ }^{\circ}$. Projeto RADAMBRASIL, Salvador. 86p. von Bayern T (2013) Viagem pelo Espírito Santo (1888): Viagem pelos trópicos brasileiros. Arquivo Público do estado do Espírito Santo, Vitória. 176p.

Zorzanelli JPF, Dias HM, Silva NR \& Kunz SH (2016a) Richness, structure and vegetation relationships of the woody layer in an upper montane forest in Caparaó National Park, Minas Gerais state, Brazil. Oecologia Australis 20: 177-183.

Zorzanelli JPF, Carrijo TT, Fiaschi P, Jardim JG, Santamaría-Aguillar D \& Amorim AM (2016b) A first record of Freziera (Pentaphylacaceae) from the Brazilian Atlantic Forest, with the description of a new species. Systematic Botany 40: 1075-1080.

Zorzanelli JPF, Dias HM, da Silva AG \& Kunz SH (2017) Vascular plant diversity in a Brazilian hotspot: floristic knowledge gaps and tools for conservation. Brazilian Journal of Botany 40: 819-827. DOI 10.1007/s40415-017-0386-z. 